\title{
Angiographic Right and Left Ventricular Volume Determination in Normal Infants and Children
}

\author{
Otto G. Thilenius ${ }^{[21]}$ and Rene A. Arcilla \\ Section of Cardiology, Department of Pediatrics, University of Chicago, Chicago, Illinois, USA
}

\begin{abstract}
Extract
Right and left ventricular volumes were calculated from bi-plane cineangiograms using a previously descriped parallelepiped method. Seventeen children, 1 month-10 years of age, were studied. Mean right ventricular end-diastolic volume (EDV) was $64 \mathrm{ml} / \mathrm{m}^{2}$ for infants, $78 \mathrm{ml} / \mathrm{m}^{2}$ for children. Mean right ventricular end-systolic volume (ESV) was $30 \mathrm{ml} / \mathrm{m}^{2}$ for both age groups. Left ventricular EDV and ESV were smaller than their right ventricular correlates by $23 \%$ and $56 \%$, respectively. Mean right ventricular ejection fraction was 0.52 for infants and 0.61 for children. Mean left ventricular ejection fraction was 0.79 and 0.74 , respectively.
\end{abstract}

\section{Speculation}

Cineangiographic determination of right and left ventricular volumes from a single contrast injection provides an excellent method to simultaneously evaluate hemodynamic performance of the two ventricles. Analysis of frame to frame volume changes, coupled with exact measurements of ventricular pressure changes, may allow calculation of ventricular distensibility and contractility.

\section{Introduction}

Angiographic methods for evaluation of left ventricular volume have become relatively standardized in recent years and are being used for adult as well as for pediatric patients [3-6, 9-18]. The area-length method of Dodge [3], which assumes an elliptoid left ventricular cavity, is commonly utilized for these volume estimates. Based on analysis of bi-plane radiographs of human ventricular casts, we have shown [1] that volumes can be calculated as well for irregularly shaped right ventricles, which suggests that the assumption of a mathematically defined ventricular cavity is not a prerequisite for such volume calculations. It was also shown that volumes calculated by the arealength and the parallelepiped $\left(\mathrm{L}_{\max }\right)$ method are highly comparable for both left and right ventricles [1].
In this paper we are reporting the clinical applicability of right ventricular volume measurements, and present quantitative data concerning normal right and left ventricular volumes in infants and children.

\section{Materials and Methods}

Seventeen children (Table I), 6 boys and 11 girls, ranging in age from 1 month to 10 years, underwent right heart catheterization, using meperidine and hydroxyzine hydrochloride $(1.8 \mathrm{mg} / \mathrm{kg}$, i.m., up to $50 \mathrm{mg}$ of each) for sedation for patients over $5 \mathrm{~kg}$ body wt. Left to right shunts were excluded by hydrogen electrode study. Fifteen of the subjects had entirely normal hemodynamics, two had minimal pulmonary valvular stenosis with a right ventricular peak systolic pressures of 32 and $40 \mathrm{~mm} \mathrm{Hg}$, respectively. After the usual diag- 
Table 1 . Data of normal infants and children ${ }^{1}$

\begin{tabular}{|c|c|c|c|c|c|c|c|c|c|c|c|c|c|c|c|c|}
\hline & \multirow{2}{*}{$\begin{array}{l}\text { Age, } \\
\text { yr }\end{array}$} & \multirow{2}{*}{$\begin{array}{l}\text { Height, } \\
\text { cm }\end{array}$} & \multirow{2}{*}{$\begin{array}{c}\text { Weight, } \\
\mathrm{kg}\end{array}$} & \multirow{2}{*}{$\begin{array}{c}\text { Heart } \\
\text { rate, } \\
\text { beats/ } \\
\text { min }\end{array}$} & \multirow{2}{*}{ BSA } & \multirow{2}{*}{ Sex } & \multicolumn{5}{|c|}{$\mathrm{RV}$} & \multicolumn{5}{|c|}{ LV } \\
\hline & & & & & & & EDV & ESV & SV & $\mathrm{EF}$ & $Q$ & EDV & ESV & SV & EF & Q \\
\hline \multicolumn{17}{|l|}{ Infants } \\
\hline$S M$ & 0.096 & 48 & 2.8 & 160 & 0.21 & $\mathrm{~F}$ & 11.3 & 5.8 & 5.5 & 0.49 & 0.88 & 6.6 & 1.3 & 5.3 & 0.80 & 0.84 \\
\hline$L C$ & 0.33 & 64 & 7.0 & 150 & 0.33 & F & 18.9 & 8.7 & 10.2 & 0.54 & 1.54 & 8.3 & 1.2 & 7.1 & 0.86 & 1.06 \\
\hline$A M L$ & 0.33 & 66 & 8.9 & 130 & 0.39 & M & 28.0 & 14.0 & 14.0 & 0.50 & 1.82 & 190 & 3.7 & 15.3 & 0.81 & 1.99 \\
\hline$M B$ & 0.5 & 64 & 7.0 & 140 & 0.33 & F & 22.3 & 10.4 & 11.9 & 0.53 & 1.67 & 14.7 & 2.7 & 12.0 & 0.81 & 1.67 \\
\hline$L D$ & 0.5 & 67 & 6.7 & 120 & 0.34 & F & 22.1 & 9.0 & 13.1 & 0.59 & 1.57 & 14.4 & 3.2 & 11.2 & 0.78 & 1.35 \\
\hline$R J$ & 0.67 & 67 & 10.3 & 140 & 0.41 & $\mathrm{~F}$ & 25.1 & 11.6 & 13.5 & 0.54 & 1.89 & 20.9 & 4.8 & 16.1 & 0.77 & 2.25 \\
\hline$A P$ & 1.08 & 72 & 9.1 & 110 & 0.41 & M & 27.9 & 15.4 & 12.5 & 0.45 & 1.37 & 24.2 & 7.6 & 16.6 & 0.69 & 1.82 \\
\hline \multicolumn{17}{|c|}{ Children } \\
\hline$R J$ & 2.3 & 90 & 12.8 & 100 & 0.56 & M & 35.8 & 15.9 & 19.9 & 0.56 & 1.99 & 28.8 & 8.4 & 20.4 & 0.71 & 2.04 \\
\hline$S A$ & 3.8 & 96 & 13.7 & 110 & 0.60 & $\mathrm{~F}$ & 38.7 & 13.5 & 25.2 & 0.65 & 2.78 & 39.5 & 10.1 & 29.4 & 0.74 & 3.23 \\
\hline$P G$ & 3.9 & 100 & 14.0 & 70 & 0.62 & $F$ & 43.1 & 17.1 & 26.0 & 0.60 & 1.82 & 34.0 & 10.1 & 23.9 & 0.70 & 1.68 \\
\hline$C W$ & 4.7 & 119 & 25.0 & 120 & 0.90 & F & 67.1 & 24.5 & 42.6 & 0.63 & 5.11 & 51.8 & 11.7 & 40.1 & 0.77 & 4.82 \\
\hline$H R$ & 4.8 & 116 & 32.0 & 120 & 0.98 & $\mathbf{M}$ & & & & & & 81.7 & 29.4 & 52.3 & 0.64 & 6.27 \\
\hline CS & 5.8 & 112 & 18.5 & 90 & 0.76 & $\mathbf{F}$ & 50.3 & 21.0 & 29.3 & 0.58 & 2.64 & 44.1 & 10.0 & 34.1 & 0.77 & 3.07 \\
\hline$S B$ & 7.2 & 115 & 23.5 & 115 & 0.91 & M & 70.0 & 28.6 & 41.4 & 0.59 & 4.76 & 52.0 & 12.4 & 39.6 & 0.76 & 4.55 \\
\hline$D L$ & 8.9 & 125 & 25.0 & 100 & 0.93 & F & 70.2 & 27.0 & 43.2 & 0.62 & 4.32 & 66.7 & 18.7 & 48.0 & 0.72 & 4.80 \\
\hline$J B$ & 9.7 & 130 & 26.0 & 97 & 0.98 & M & 99.2 & 43.0 & 56.2 & 0.57 & 5.46 & & & & & \\
\hline$D P$ & 10.3 & 127 & 23.0 & 90 & 0.92 & F & 99.8 & 30.5 & 69.3 & 0.69 & 6.24 & 82.7 & 16.1 & 66.6 & 0.81 & 5.99 \\
\hline
\end{tabular}

1 BSA: body surface area; RV: right ventricle; LV: left ventricle; EDV: end-diastolic volume (milliliters); ESV: end-systolic volume (milliliters); SV: stroke volume (milliliters); EF : ejection fraction; Q: ventricular output (liters per minute); M: male; F : female.

nostic procedures, bi-plane cineangiograms were obtained using 9-inch Philips image intensifiers and 35$\mathrm{mm}$ cameras with a filming rate of 30 frames/sec. Contrast material (Renografin 76, up to $2 \mathrm{ml} / \mathrm{kg}$ ) was injected with a Cordis injector at a maximal allowable pressure into the right atrium. The right atrium was selected as the injection site to avoid ectopic beats which invalidate volume calculations. The images of the ventricular chambers were traced on paper using a Tagarno 35 projector with a fixed projection distance. The areas of the traced images were obtained with a Hewlett-Packard digitizer, and were corrected for x-ray magnification using separate correction factors for each ventricle in each plane, depending on the respective distances of each chamber from the frontal and lateral grids. These distances were determined as follows. The center of the frontal image intensifier, which had a fixed distance from the lateral tube, was photographed with a lead marker during each angiogram. This center marker served as a reference point for superimposition of a calibrated grid during projection of the film; the latter grid was used to determine the distance of the geometric center of each ventricular chamber from the lateral grid. To estimate the average distance of the heart chambers from the frontal grid, a marker chain was suspended immediately in front of the lateral grid and recorded just before angiocardiography to determine the center of the lateral image intensifier tube (lead marker) above the frontal x-ray grid. Again, superimposition of a calibrated grid dur- ing projection of the cine film permitted measurement of the distance of each ventricle from the frontal grid. In our experience this method is simple and sufficiently accurate, provided that $\mathrm{x}$-ray images are within a critical area of insignificant nonlinear x-ray distortion. This critical area of linear x-ray magnification has, for our system, been delineated within a $5-\mathrm{cm}$ radius from the center of the image intensifier tubes.

Because the accuracy of the ventricular silhouette as traced on paper is critical for the reliability of the volume estimates, the two authors examined each angiogram independently. These two sets of data were statistically compared. As there was no significant difference, the data were then averaged.

After correction of the planimetered areas and long axes for $\mathrm{x}$-ray magnification, the following equation was employed for the volume calculation (see Reference 1, parallelepiped $\left(\mathrm{L}_{\max }\right)$ method): $\mathrm{V}_{\mathrm{E}}=\mathrm{A}_{\mathrm{f}} \mathrm{A}_{1} / \mathrm{L}_{\max }$. $V_{E}$ is then corrected by the use of the following regression equations: right ventricle, $\mathrm{V}_{\mathrm{C}}=0.752 \mathrm{~V}_{\mathrm{E}}+$ 2.81; left ventricle, $\mathrm{V}_{\mathrm{C}}=0.847 \mathrm{~V}_{\mathrm{E}}-0.80\left(\mathrm{~A}_{\mathrm{f}}\right.$, area in frontal plane; $A_{1}$, area in lateral plane; $L_{\max }$, maximal apex-base length of chamber in frontal plane (for left ventricle) or in lateral plane (for right ventricle); $V_{E}$, estimated chamber volume; $V_{\mathrm{C}}$, corrected chamber volume).

For comparative purposes, left ventricular volumes were also calculated with the area-length method, using the revised regression equations of Graham et al. [10] for volumes above and below $15 \mathrm{ml}$. 


\section{Statistical Methods}

The Student $t$ test was used for analysis of the ventricular volumes and ejection fractions, accepting a $2 P$ value of $<0.05$ as significant. Simple and multiple variable regression equations were computed, using the method of least squares.

\section{Results}

All volume data given in Table I are averages of the independent determinations of the two authors. The reliability of such averages is strengthened if the individual values, obtained separately by different observers, are comparable and reproducible. This is shown in Figure 1 where the end-diastolic volume calculations for both ventricles are compared in one graph and the end-systolic volumes in another. For end-diastolic volumes, the two sets of calculations were almost identical
(Fig. 1a), with a $10 \%$ sD. For end-systolic volumes, where the cine images are less sharply outlined, a $20 \%$ sD was observed.

Right ventricle. End-diastolic volume. Right ventricular end-diastolic volume ranged from $11.3 \mathrm{ml}$ for the smallest infant to $99.8 \mathrm{ml}$ for the oldest child. When normalized for body surface area (Table II), infants up to 13 months had significantly $(2 P<0.05)$ lower values $\left(63.6 \mathrm{ml} / \mathrm{m}^{2}\right)$ than children $\left(77.9 \mathrm{ml} / \mathrm{m}^{2}\right)$.

End-systolic volume. Right ventricular end-systolic volume ranged from 5.8 to $43.0 \mathrm{ml}$. There was no difference in normalized end-systolic volume between infants and children, the mean values being 30.6 and $30.1 \mathrm{ml} / \mathrm{m}^{2}$.

Stroke volume. Right ventricular stroke volume ranged from 5.5 to $69.3 \mathrm{ml}$. The mean normalized stroke volume for infants was $33.0 \mathrm{ml} / \mathrm{m}^{2}$, significantly lower than that for children $\left(47.8 \mathrm{ml} / \mathrm{m}^{2}\right)$.
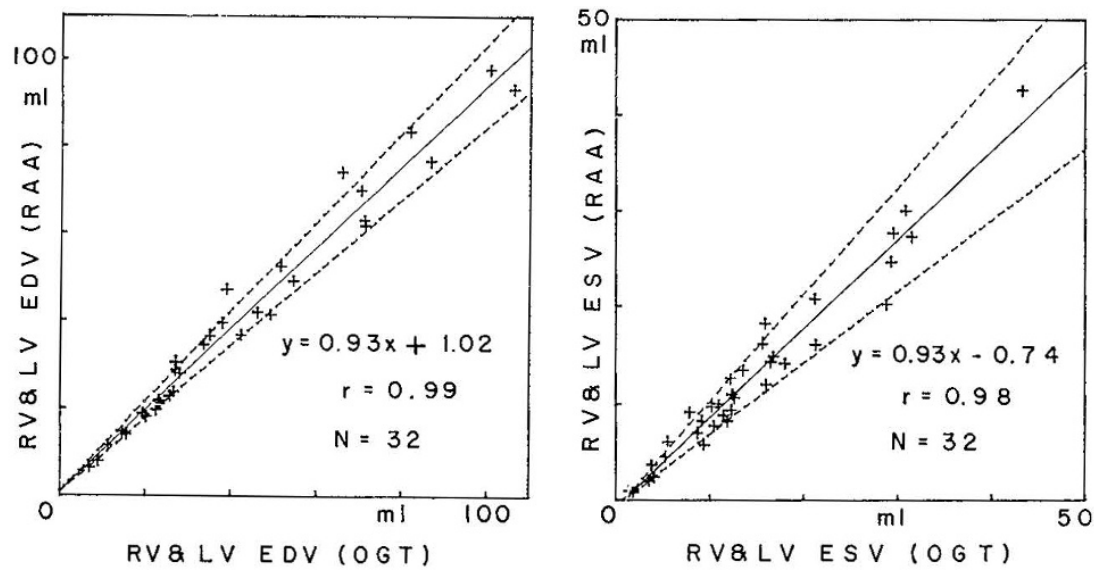

Fig. 1. Comparison ot volume calculations of the two authors for right ventricular $(R V)$ and left ventricular $(L V)$ end-diastolic $(l e f t)$ and end-systolic (right) volumes (EDV and ESV, respectively). The differences were statistically not significant. ( $r$ : correlation coefficient, $N$ : number of data points.) —-: linear regression; - - \pm 1 SD (in percentage).

Table II. Normalized ventricular volumes of normal infants and children ${ }^{1}$

\begin{tabular}{|c|c|c|c|c|c|c|c|c|c|c|c|}
\hline \multirow{2}{*}{ Age } & \multirow{2}{*}{$\begin{array}{l}\text { No. } \\
\text { of } \\
\text { sub- } \\
\text { jects }\end{array}$} & \multirow{2}{*}{ BSA } & \multirow{2}{*}{ HR } & \multicolumn{4}{|c|}{ Right ventricle ${ }^{2}$} & \multicolumn{4}{|c|}{ Left ventricle ${ }^{2}$} \\
\hline & & & & EDV & ESV & SV & $\mathrm{EF}$ & EDV & ESV & SV & $\mathrm{EF}$ \\
\hline $1-13 \mathrm{mo}$ & 7 & $0.21-0.41$ & $110-160$ & $\begin{array}{r}63.6 \\
\pm 6.3\end{array}$ & $\begin{array}{r}30.6 \\
\pm 4.6\end{array}$ & $\begin{array}{r}33.0 \\
\pm 4.1\end{array}$ & $\begin{array}{r}0.52 \\
\pm 0.04\end{array}$ & $\begin{array}{r}43.1 \\
\pm 11.6\end{array}$ & $\begin{array}{r}9.6 \\
\pm 4.7\end{array}$ & $\begin{array}{r}33.5 \\
\pm 7.5\end{array}$ & $\begin{array}{r}0.79 \\
\pm 0.05\end{array}$ \\
\hline $2-10 \mathrm{yr}$ & 9 & $0.56-0.98$ & $70-120$ & $\begin{array}{r}77.9 \\
\pm 16.1\end{array}$ & $\begin{array}{r}30.1 \\
\pm 5.9\end{array}$ & $\begin{array}{r}47.8 \\
\pm 12.1\end{array}$ & $\begin{array}{r}0.61 \\
\pm 0.04\end{array}$ & $\begin{array}{r}65.6 \\
\pm 13.6\end{array}$ & $\begin{array}{r}17.3 \\
\pm 5.3\end{array}$ & $\begin{array}{r}48.3 \\
\pm 10.6\end{array}$ & $\begin{array}{r}0.74 \\
\pm 0.05\end{array}$ \\
\hline $2 \mathrm{P}$ values & & & & $<0.05$ & N.S. & $<0.01$ & $<0.01$ & $<0.01$ & $<0.01$ & $<0.01$ & $<0.10$ \\
\hline
\end{tabular}

${ }^{1}$ BSA : body surface area; HR : heart rate; EDV : end-diastolic volume; ESV : end-systolic volume; EF : ejection fraction; N.S. : not significant.

2 All volumes are expressed in milliliters per square meter; mean $\pm 1 \mathrm{SD}$. 
Ejection fraction. For the right ventricle the mean ejection fraction of infants, $0.52 \pm 0.04 \mathrm{sD}$, was significantly lower than for children, $0.61 \pm 0.04 \mathrm{sD}$.

Cardiac output. Cardiac output for the right ventricle ranged from 0.88 to 6.24 liters $/ \mathrm{min}$, and correlated very well with left ventricular output $(r=0.98$, Fig. 2$)$, with a $15.4 \%$ sD.

Left ventricle. End-diastolic volume. Left ventricular end-diastolic volume was, almost without exception, smaller $(0-56 \%$, mean $23 \%)$ than right ventricular end-diastolic volume (Fig. 3). It ranged from 6.6 to $82.7 \mathrm{ml}$. The mean value (Table II) was $43.1 \mathrm{ml} / \mathrm{m}^{2}$ for infants; it was significantly lower than that observed for children $\left(65.6 \mathrm{ml} / \mathrm{m}^{2}\right)$.

End-systolic volume. Left ventricular end-systolic

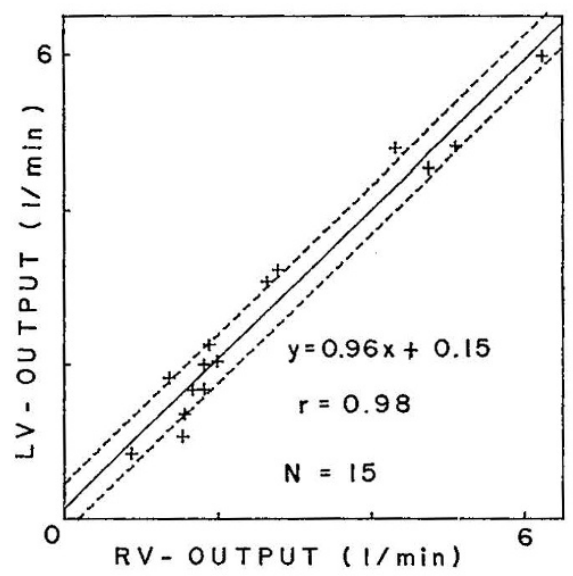

Fig. 2. Right ventricular $(R V)$ and left ventricular $(L V)$ output in liters per minute, calculated from bi-plane cineangiograms using the parallelepiped $\left(\mathbf{L}_{\max }\right)$ method [1]. - ${ }_{-}$linear regression; - - $: \pm 1$ SD (in milliliters).

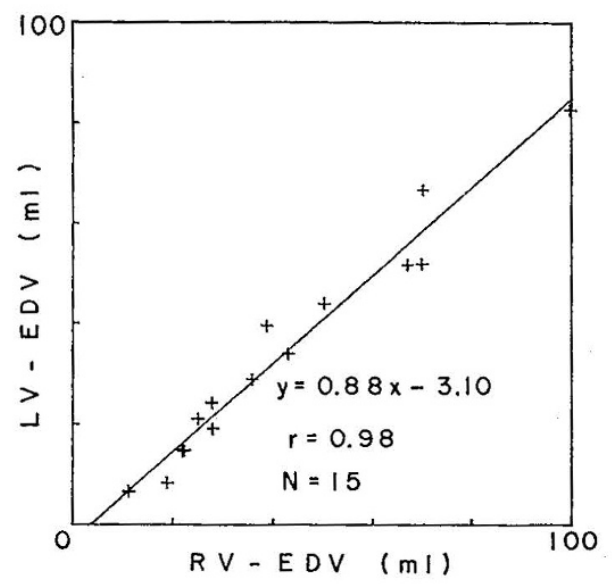

Fig. 3. Comparison of right ventricular $(R V)$ and left ventricular $(L V)$ end-diastolic volume $(E D V)$. - - linear regression.
Table III. Single correlations ${ }^{1}$

\begin{tabular}{lllll}
\hline & \multicolumn{4}{c}{ r values } \\
\cline { 2 - 5 } & Age & Height & Weight & Heart rate \\
\hline Infants & & & & \\
RV & & & & \\
EDV & 0.84 & 0.95 & 0.96 & -0.89 \\
ESV & 0.87 & 0.90 & 0.92 & -0.87 \\
SV & 0.75 & 0.95 & 0.94 & -0.85 \\
LV & & & & \\
EDV & 0.92 & 0.89 & 0.93 & -0.89 \\
ESV & 0.96 & 0.84 & 0.84 & -0.90 \\
SV & 0.87 & 0.89 & 0.95 & -0.86 \\
Children & & & & \\
RV & & & & \\
EDV & 0.96 & 0.96 & 0.92 & 0.26 \\
ESV & 0.92 & 0.94 & 0.92 & 0.30 \\
SV & 0.95 & 0.94 & 0.89 & 0.22 \\
LV & & & & \\
EDV & 0.85 & 0.92 & 0.93 & 0.54 \\
ESV & 0.57 & 0.73 & 0.92 & 0.62 \\
SV & 0.91 & 0.94 & 0.88 & 0.47 \\
\hline
\end{tabular}

${ }^{1} \mathrm{RV}$ : right ventricle; EDV: end-diastolic volume; ESV: endsystolic volume; SV: stroke volume; LV : left ventricle.

volume was, in all patients, smaller $(25-86 \%$, mean $56 \%)$ than right ventricular end-systolic volume. It ranged from between 1.2 and $1.3 \mathrm{ml}$ for our two smallest subjects to $29.4 \mathrm{ml}$. The normalized mean values were again significantly different between the infants $\left(9.6 \mathrm{ml} / \mathrm{m}^{2}\right)$ and the children $\left(17.3 \mathrm{ml} / \mathrm{m}^{2}\right)$.

Stroke volume. Left ventricular stroke volume showed high correlation with right ventricular stroke volume $(\mathrm{r}=0.98)$. It was $33.5 \mathrm{ml} / \mathrm{m}^{2}$ for the infant group and $48.3 \mathrm{ml} / \mathrm{m}^{2}$ for the older group.

Ejection fraction. Left ventricular ejection fractions were higher than those of the right ventricle, a consequence of the comparatively smaller left ventricular end-diastolic and end-systolic volumes. The mean values were $0.79 \pm 0.05 \mathrm{SD}$ for infants, and $0.74 \pm 0.05 \mathrm{SD}$ for children.

Cardiac output. Left ventricular cardiac output ranged from 0.84 to 6.27 liters/min and was highly comparable with that of the right ventricle (Fig. 2).

Prediction of normal ventricular volume. Inasmuch as ventricular volume may be expected to increase with body growth, several single correlations related to growth were calculated (Table III). By far the best correlation was found for five-variable regression equations, using age, height, weight, and heart rate as simultaneous, independent variables. These results are given in Table IV and are, for the right ventricle, shown in Figure 4. 
Table $I V$. Multiple regression equations for prediction of ventricular volume of normal infants and children ${ }^{1}$

\begin{tabular}{|c|c|c|c|}
\hline & $\mathrm{R}$ & $\pm 1 \mathrm{sD}, \mathrm{ml}$ & $\pm 2 \mathrm{SD}, \%$ \\
\hline \multicolumn{4}{|l|}{ Infants, up to $2 \mathrm{yr}$} \\
\hline \multicolumn{4}{|l|}{ Right ventricle } \\
\hline $\mathrm{EDV}=44.134-4.325$ age -0.121 height +2.077 weight -0.202 heart rate & 0.98 & 1.16 & 10.2 \\
\hline $\mathrm{ESV}=35.102+0.855$ age -0.271 height +1.274 weight -0.125 heart rate & 0.92 & 1.28 & 22.0 \\
\hline $\mathrm{SV}=9.032-5.180$ age +0.150 height +0.803 weight -0.077 heart rate & 0.98 & 0.65 & 11.4 \\
\hline \multicolumn{4}{|l|}{ Left ventricle } \\
\hline $\mathrm{EDV}=88.151+6.641$ age -0.935 height +3.040 weight -0.285 heart rate & 0.99 & 0.83 & 13.4 \\
\hline $\mathrm{ESV}=29.499+5.211$ age -0.333 height +0.697 weight -0.092 heart rate & 0.99 & 0.20 & 18.9 \\
\hline $\mathrm{SV}=58.652+1.431$ age -0.602 height +2.343 weight -0.193 heart rate & 0.98 & 0.87 & 17.9 \\
\hline \multicolumn{4}{|l|}{ Children, $2.0-10 \mathrm{yr}$} \\
\hline \multicolumn{4}{|l|}{ Right ventricle } \\
\hline $\mathrm{EDV}=-59.754+4.343$ age +0.808 height -0.174 weight +0.088 heart rate & 0.94 & 7.93 & 25.2 \\
\hline $\mathrm{ESV}=34.423+1.788$ age -0.398 height +1.786 weight -0.124 heart rate & 0.90 & 3.88 & 26.9 \\
\hline $\mathrm{SV}=-94.177+2.554$ age +1.205 height -1.960 weight +0.213 heart rate & 0.92 & 6.15 & 30.9 \\
\hline \multicolumn{4}{|l|}{ Left ventricle } \\
\hline $\mathrm{EDV}=75.130+5.473$ age -0.942 height +3.249 weight -0.158 heart rate & 0.94 & 6.79 & 24.5 \\
\hline $\mathrm{ESV}=62.324+1.548$ age -0.748 height +1.960 weight -0.147 heart rate & 0.95 & 2.03 & 36.7 \\
\hline $\mathrm{SV}=12.807+3.925$ age -0.195 height +1.288 weight -0.011 heart rate & 0.93 & 5.43 & 23.7 \\
\hline
\end{tabular}

${ }^{1}$ Age in years; height in centimeters; weight in kilograms; R: multiple correlation coefficient; sD : standard deviation of predicted value in milliliters and calculated as (observed value)/(predicted value) $\times 100$ (percentage of predicted value); EDV: end-diastolic volume; ESV: end-systolic volume; SV: stroke volume.

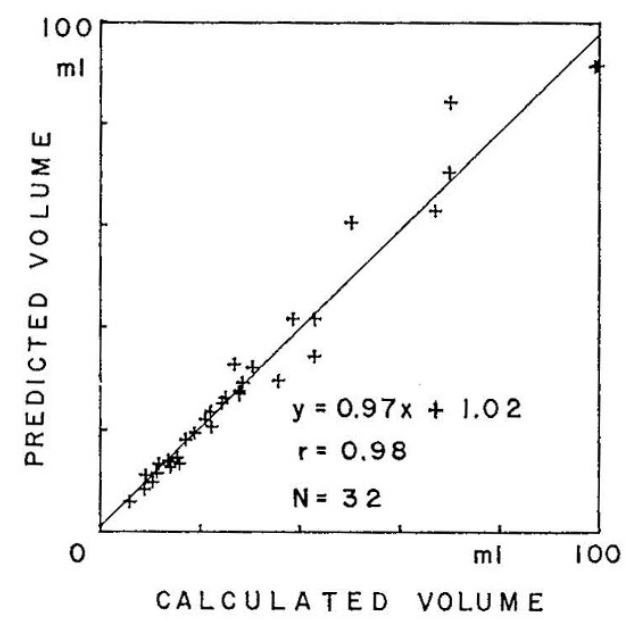

Fig. 4. Comparison of calculated and predicted right ventricular end-diastolic and end-systolic volumes. —- linear regression.

Comparison of area-length and parallelepiped methods. Because the area-length method [3] has been the standard method used for most reported left ventricular volume calculations, left ventricular end-diastolic and end-systolic volumes calculated by the arealength and by the parallelepiped $\left(\mathrm{L}_{\max }\right)$ method were compared (Fig. 5). Using the two separate correcting regression equations of Graham et al. [10] for volumes smaller or larger than $15 \mathrm{ml}$ in the area-length method, the results obtained from the parallelepiped and area-length methods are highly similar $(r=0.99)$,

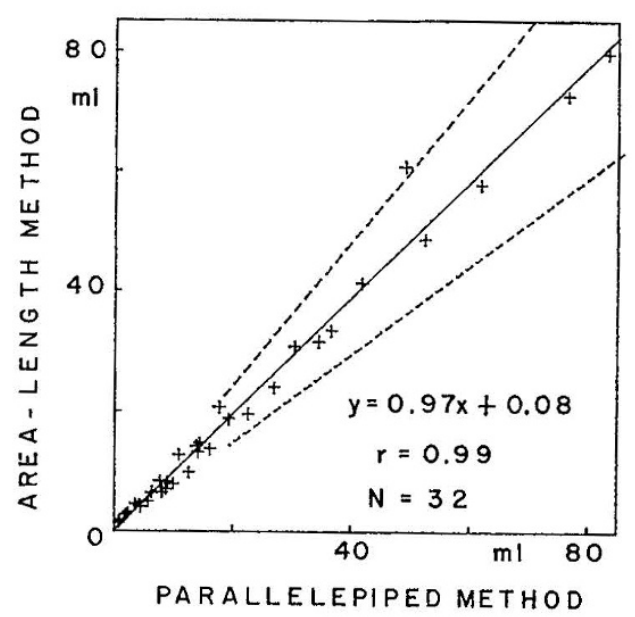

Fig. 5. Comparison of left ventricular end-diastolic and endsystolic volumes calculated with the parallelepiped method (ab. scissa) and the area-length method (ordinate) using the Graham et al. regression equations [10]. - linear regression; -- -: $\pm \mathrm{I}$ sD (in percentage).

with the regression equation: area-length volume (ml) $=0.968$ parallelepiped volume +0.078 . Furthermore, we compared the parallelepiped $\left(\mathrm{L}_{\max }\right)$ method with the area-length method using our own [1] correcting regression equation equally applicable to both infants and children. Again, a very high correlation was found, $r=0.99$, with the regression equation: arealength volume (milliliters) $=1.00$ parallelepiped volume +1.20 (Fig. 6). 


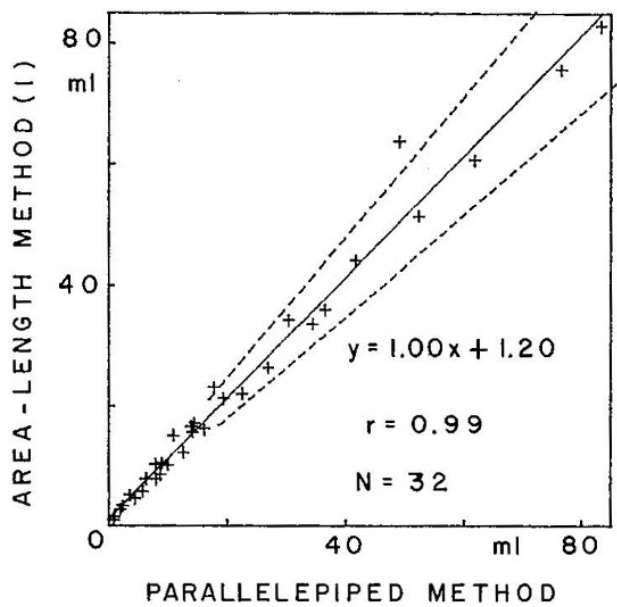

Fig. 6. Comparison of left ventricular end-diastolic and end-systolic volumes calculated with the parallelepiped method ( $a b$ scissa) and the area-length method (ordinate) using the Arcilla et al. regression equation [1]. - - linear regression; ---: \pm 1 SD (in percentage).

\section{Discussion}

In an earlier paper [1] we demonstrated that the volume of human right ventricular casts can be calculated from bi-plane radiographs with a high degree of accuracy in spite of their variable geometric configurations. This accuracy applied to casts of normal right and left ventricles, as well as of ventricles of patients with congenital heart disease. It remained to be shown that this method is applicable to bi-plane angiocardiograms obtained during routing cardiac catheterization.

Because volume calculations are meaningful only in the absence of arrhythmia, right atrial contrast injection was used for all our studies. This approach also avoids iatrogenic tricuspid regurgitation which would result in fortuitously larger right ventricular volumes. In spite of this precaution, a small number of patients had atrial ectopic beats during the contrast injection; the angiograms of such patients were not included in this study.

Right atrial contrast injection poses some difficulty in analyzing angiograms for right ventricular volume calculations because of the partial overlapping of the right atrium and right ventricle, particularly in the lateral projection. Accurate reproduction of the cavitary images requires considerable care, familarity with ventricular anatomy, and, of course, a technically satisfactory angiogram. These requirements can be met by a trained and careful worker but hardly by a computer or novice.

Because the most critical part in angiographic volume calculations is the correct tracing of the ventricu- lar silhouette, the small, statistically insignificant difference between the data of the two observers is good evidence for the reproducibility of the method.

Previous authors $[5,12,14,17]$ have shown that left ventricular output determined angiographically with the area-length method agrees closely with that obtained by the Fick or dye dilution method. In our studies it was not possible to use simultaneously an independent method of cardiac output determination for comparison with the angiographic data. Indirect evidence for the reliability of the angiographic parallelepiped ( $\left.\mathrm{L}_{\max }\right)$ method for right ventricular volume is (1) the highly comparable right and left ventricular stroke volume in this group of subjects $(r=0.98)$, and (2) the high correlation of the parallelepiped method and the area-length method $(r=0.99)$. The similarity of the left ventricular end-diastolic volume data (normalized for body surface area) of our study to those reported by other authors for both children $[5,6,16]$ and adults [12, 17] are also indirect arguments.

For comparative purposes the earlier study of Graham et al. [9] on left ventricular volumes of normal children and their more recent re-evaluation [10] are of particular relevance. These authors used the arealength method, combined with corrective regression equations derived from studies in vitro of contrastdistended dog hearts and some human heart casts. Graham et al. $[9,10]$ reported a significant quantitative difference in left ventricular volumes of infants and children just as in our studies. However, although the end-diastolic volumes observed in their studies are nearly identical with our data, the end-systolic volumes for the infants and children were approximately $30-40 \%$ larger than our values. Consequently, stroke volume and left ventricular ejection fractions observed by these authors were lower than those in our group of subjects. The cause of this difference is unexplained; it does not reside in the different methodology and the use of different corrective regression equations, inasmuch as Figure 5 shows that both methods, applied to the same basic data, result in nearly identical volumes.

Right ventricular volumes of normal subjects were reported in 1971 by Carlson et al. [2] and recently in three studies $[6,7,8]$, which used different geometrical figures and corrected regression equations as the basis for the calculations. Carlson's data [2] for right ventricular end-diastolic and end-systolic volume (milliliters per square meter) are only $50-60 \%$ of our values, whereas the data of Fisher et al. [6], Gentzler et al. [7] and Graham et al. [8] approximate those of ours, particularly for children. 
Comparison of the respective volumes of the right and left ventricle demonstrates consistently larger $(P$ $<0.01$ ) end-systolic and end-diastolic volume of the right ventricle (Fig. 3), most likely accounted for by the different geometry of the two ventricles as well as the higher compliance of the right ventricular wall. For the same reason right ventricular ejection fraction is lower than its left-sided counterpart. We attempted to correlate ejection fraction with heart rate in the infants and in the children separately to check whether the lower values were observed with higher heart rates. However the scatter of the ejection fraction data was too marked, and a significant correlation could not be shown. Further data are necessary to clarify this question.

Because end-diastolic volume of the ventricles is, at least within limits, a function of the duration of its diastolic filling, it should decrease with faster heart rates. Kennedy et al. [14] described a linear relation of left ventricular end-diastolic volume and heart rate in normal adult subjects for heart rates of $50-100 / \mathrm{min}$. A similar correlation was noted for our infant group (Table III); for older children the scatter of the data points did not permit a meaningful analysis.

Angiographic determination of right and left ventricular volumes during routine cardiac catheterization provides a relatively easy, fast, and safe method of quantitating hemodynamic data not available in the past. In patients with mitral or aortic insufficiency, regurgitant fraction can be calculated from the difference between right and left ventricular stroke volumes. Ejection fractions give insight into the effectiveness of ventricular contraction. Comparisons of ventricular end-systolic and end-diastolic volume with its normally expected value, taking into consideration age, weight, height, and heart rate, give a good estimation of the degree of ventricular enlargement. Extended applications of this method pertain to analysis of angiograms for frame to frame volume changes and, coupled with exact measurements of ventricular pressure changes, allow calculation of ventricular distensibility and contractility. Finally, this approach would enable comparative analysis of right and left ventricular function in predominantly right-sided or left-sided lesions, previously not possible because of lack of a reliable method for right ventricular volume determination.

\section{Summary}

Right and left ventricular volumes were calculated from biplane cineangiograms. Of 17 children studied, 1 month-10 years of age, 15 had normal hemodynamic data and 2 had minimal pulmonary valvar stenosis. Left and right ventricular stroke volumes were virtually identical $(r=0.98)$. End-diastolic volume, end-systolic volume, and stroke volume of both ventricles showed good correlation $(r=0.86-0.99)$ to age, height, weight, and heart rate as simultaneous independent variables. For each child, left ventricular end-diastolic volume and end-systolic volume were smaller than their right ventricular correlates by $23 \%$ and $56 \%$, respectively. Mean right ventricular ejection fraction was 0.52 for infants and 0.61 for children. Mean left ventricular ejection fractions were 0.79 and 0.74 , respectively.

\section{References and Notes}

1. Arcilla, R. A., Tsai, P., Thilenius, O. G., and Ranniger, K.: Angiographic method for volume estimation of right and left ventricles. Chest, 60: 446 (1971).

2. Carlson, E., Keene, R. J., Lee, P., and Goercke, R. J.: Angiocardiographic stroke volume correlation of the two cardiac ventricles in man. Invest. Radiol., 6: 44 (1971).

3. Dodge, H. T., SAndler, H., Ballew, D. W., and Lord, J. D.: The use of biplane angiography for the measurement of left ventricular volume in man. Amer. Heart J., 60: 762 (1960).

4. DOdge, H. T., LoRd, J. D., AND SANDler, H.: Cardiovascular effects of isoproterenol in normal and congestive heart failure subjects. Amer. Heart J., 60: 94 (1960).

5. DODGE, H. T., HAY, R. E., AND SANDLER, H.: An angiocardiographic method for directly determining left ventricular stroke volume in man. Circ. Res., 11: 739 (1962).

6. Fisher, E. A., DuBrow, I. W., and Hastreiter, A. R.: Right ventricular volume determination in infants and children. Amer. J. Cardiol., 31: 131 (1973).

7. Gentzler, R. D., Gault, J. H., and Briselli, M. F.: Angiographic estimation of right ventricular volume in man. Amer. J. Cardiol., 31: 134 (1973).

8. Graham, T. P., Jarmakani, M. M., Atwood, G. F., and CANENT, R. V.: Right ventricular volume determinations in children: Normal values and observations with volume or pressure overload. Circulation, 47: 144 (1973).

9. Graham, T. P., JR., Jarmakani, M. M., Canent, R. V., JR., CAPP, M. P., AND SPACH, M. S.: Characterization of the heart volumes and mass in normal children and infants with intrinsic myocardial disease. Circulaiton, 38: 826 (1968).

10. Graham, T. P., Jarmakani, M. M., Jr., Canent, R. V., JR., AND MoRrow, M. N.: Left heart volume estimation in infancy and childhood. Circulation, 43: 895 (1971).

11. Greene, D., Carlisle, R., Grant, C., and Bunnelt, I.: Estimation of left ventricular volume by one-plane cineangiography. Circulation, 34: 61 (1967).

12. GribBE, P.: Comparison of angiocardiographic and direct Fick methods in determining cardiac output. Cardiologia, 36: 20 (1960).

13. Jarmakani, M. M., Graham, T. P., Jr., Canent, R. V., Spach, M. S., AND CAPP, M. P.: Effect of site of shunt on left heartvolume characteristics in children with ventricular septal defect and patent ductus arteriosus. Circulation, 40: 411 (1969).

14. Kennedy, J. W., Baxley, W. A, Figlex, M. M., Dodge, H. D., 
and Blackman, J. R.: Quantitative angiography. I. The normal left ventricle in man. Circulation, 34: 272 (1966).

15. Kennedy, J. W., Trenholme, S. E., and Kasser, I. S.: Left ventricular volume and mass from single-plane cineangiogram. A comparison of antero-posterior and right anterior oblique methods. Amer. Heart J., 80: 343 (1970).

16. Kennedy, J. W., Twiss, R. D., Blackman, J. R., and Dodge, H. T.: Quantitative angiocardiography. III. Relationships of left ventricular pressure, volume and mass in aortic valve disease. Circulation, 38: 838 (1968).

17. Miller, G. A. H., ANd Swan, H. J. C.: Effect of chronic pressure and volume overload on left heart volumes in subjects with congenital heart disease. Circulation, 30: 205 (1964).
18. SANDLER, H., AND Dodge, H. T.: Left ventricular tension and stress in man. Circ. Res., 13: 91 (1963).

19. Sanmarco, M. E., AND BartLE, S. H.: Left ventricular volume determinations: comparison of angiographic and thermal washout techniques. Circulation, 30 (Suppl. 3): 151 (1964).

20. This investigation was supported by Grant no. RR-305 from the General Clinical Research Centers Program of the Division of Research Resources, National Institutes of Health.

21. Requests for reprints should be addressed to: Orto G. THILenius, M.D., Ph.D., The University of Chicago, Department of Pediatrics, 5825 Maryland Ave., Chicago, Ill. 60637 (USA).

22. Accepted for publication September 12. 